\title{
Cognitive Effect of Standardized group education programme in Diabetic population
}

Ravi Kant', Meenakshi Khapre 2 , Amninder Singh ${ }^{3}$

'Associate Professor, Department of General Medicine, All India Institute of Medical Sciences, Rishikesh,

${ }^{2}$ Assistant Professor, Department of Community and Family Medicine, All India Institute of Medical Sciences, Rishikesh, ${ }^{3}$ MBBS Intern, All India Institute of Medical Sciences, Rishikesh

\begin{abstract}
Background: The prevalence of diabetes in India has reached alarming levels with $8.7 \%$ of population affected as of 2015 , which is expected to double in the future. The reasons for the rapid increase in prevalence of diabetes include genetic predilection of Indian population, economic boom, sedentary lifestyle, inadequate follow up and lack of disease awareness. The aim of the study was to overcome the self care deficit which would help patients to be more compliant and better in managing their illness.
\end{abstract}

Methods: The study was conducted at weekly diabetes clinic at AllMS, Rishikesh in which 200 patients participated. Two sessions, each of 60 minutes were conducted fortnightly. The patients were educated by trained personnel using specially designed module in patients' own language. Each group consisted of 10- 15 participants. Participants were tested at the beginning and after the educational programme using a 10 item questionnaire. Data was analysed using MS Excel 2010. Paired t test was used to find any significant difference between pre and post test score.

Results: A significant improvement in test scores after education session was noted. Average learning gain was $77.98 \% \pm 23.27 \%$ after the group education. Sixty four percent participants demonstrated more than $75 \%$ learning gain.

Conclusion: A dedicated group session programme implemented in an environment conducive to learning with specially designed module has a significant impact on patients' knowledge (64\% participants demonstrated more than $75 \%$ learning gain) about the cause and treatment of their disease. The study can be extended to see if it impacts behaviour by tracing changes in glycaemic control.

Keywords: cognitive; diabetes; education

\section{INTRODUCTION}

Indian diabetes federation had mentioned 69.1 million cases of diabetes in India in 2015 with prevalence of $8.7 \%$ that will be doubling in near future'. Indian healthcare professionals and patients in India face a number of challenges such as clinical inertia in achieving glycaemic control, inadequate follow-up and lack of disease awareness. ${ }^{2,3}$

Correspondence: Dr. Ravi Kant, Associate Professor, Department of General Medicine, All India Institute of Medical Sciences, Virbhadra Marg, Rishikesh, Uttarakhand. Pin - 249203, Phone: 8475000266, Email: drkantr2006@gmail.com
Orem theory of self-care is framework for integration of self-care concept into patient education and adherence. Self-care is behaviour from life situation that person directs to themselves or their environment to regulate factors affecting their own development, health or wellbeing. It is a learnt and goal oriented behaviour ${ }^{4}$. Self-care deficit exists when self-care demand is not met for which patient education is the solution. The American Diabetes Association recommends assessment of self-management skills and knowledge of diabetes at least annually, and the provision or encouragement of continuing diabetes education ${ }^{5}$ 
This study is done to overcome the self care deficit which would help patients to be more compliant and better in managing their illness.

\section{METHODS}

This study was conducted in weekly diabetes clinic of All India Institute of Medical Sciences, Rishikesh. Type 2 diabetes patients of Rishikesh, regardless of how long they had been living with diabetes, with low functional health literacy attending the diabetes OPD were included in the study. The Ethical approval was given by the Institutional Ethics Committee.

Two hundred patients were recruited after obtaining their consent. Participants were pre- informed of their sessions either by phone or message. Two sessions were conducted fortnightly. Each group consisted of 10- 15 participants excluding the support i.e. family members. Each session was conducted for a period of $60 \mathrm{~min}$ followed by discussion, recall, comprehension and feedback thereby completing the communication loop8. Trained junior resident and health worker facilitated the sessions. Module was prepared by expert faculties in diabetes and tailored to the needs of the patients in Hindi language. Interactive sessions in the form of videos, Power Points and problem solving were held.

The topics included were as given by National Standards for DSME5.

- Describing the diabetes disease process and treatment options

- Incorporating nutritional management into lifestyle

- Incorporating physical activity into lifestyle

- Using medication(s) safely and for maximum therapeutic effectiveness

- Monitoring blood glucose and other parameters and interpreting and using the results for self-management decision making

- Preventing and delaying complications

- Developing personal strategies to address psychosocial issues and concerns

They were given some task on basis of topic taught to transfer the knowledge in everyday life which was reviewed in next session. Defaulters were motivated to attend next sessions.

Disease knowledge test was used to evaluate basic knowledge about diabetes. Participants were tested at the beginning and after the educational program. A 10-item questionnaire was used to assess diabetes-related knowledge and self-care practices, each answer scoring one point, up to a maximum of 10.

Data was analysed using MS Excel 2010. Paired t test was used to find any significant difference between pre and post test score. Average learning gain was computed by Pre post / 10- pre X100.

\section{RESULTS}

In this study there were 93 (46.5\%) female participants and 107 (53.5\%) males. Maximum females were between $40-50$ years (34.4\%). Maximum males were in age group of $60-70$ years (42.99\%). Overall $36 \%$ were in age group of $60-70$ years followed by $40-50$ years $(24.5$ $\%)$ and $50-60$ years (21.5\%) (Table 1).

Table 1. Age and sex distribution of participants

\begin{tabular}{|c|c|c|c|}
\hline \multirow{2}{*}{ Age } & \multicolumn{2}{|c|}{ sex } & \multirow{2}{*}{ Total } \\
\cline { 2 - 3 } & $\mathbf{F}$ & $\mathbf{M}$ & \\
\hline $20-30$ & $1(0.01 \%)$ & $3(2.8 \%)$ & $4(2 \%)$ \\
\hline $30-40$ & $12(12.9 \%)$ & $15(14.01 \%)$ & $27(13.5 \%)$ \\
\hline $40-50$ & $32(34.4 \%)$ & $17(15.89 \%)$ & $49(24.5 \%)$ \\
\hline $50-60$ & $19(20.4 \%)$ & $24(22.4 \%)$ & $43(21.5 \%)$ \\
\hline $60-70$ & $26(27.95 \%)$ & $46(42.99 \%)$ & $72(36 \%)$ \\
\hline $70-80$ & $3(0.032 \%)$ & $1(0.93 \%)$ & $4(2 \%)$ \\
\hline$>80$ & 0 & $1(0.93 \%)$ & $1(0.5 \%)$ \\
\hline Total & $93(100 \%)$ & $107(100 \%)$ & $200(100 \%)$ \\
\hline 8. Average learning gain was $77.98 \% \pm 23.27 \%$
\end{tabular}

8. Average learning gain was $77.98 \% \pm 23.27 \%$ after the group education (Table 2).

Table 2. Changes in Pre-test and post-test score after Standardized group education

\begin{tabular}{|c|c|c|}
\hline Score & Pre test score & Post test score \\
\hline$<5$ & $73(36.5 \%)$ & $4(2 \%)$ \\
\hline $5-8$ & $112(56 \%)$ & $62(31 \%)$ \\
\hline$>8$ & $15(7.5 \%)$ & $134(67 \%)$ \\
\hline Total & $200(100 \%)$ & $200(100 \%)$ \\
\hline Mean & 5.29 & 8.79 \\
\hline SD & 2.111 & 1.448 \\
\hline Paired t test & $31.27 \mathrm{P}=0.0001$ \\
\hline
\end{tabular}


There was no sex wise difference in learning gain among participants(Table 3). Sixty four percent of participants demonstrated more than $75 \%$ of learning gain. While geriatric participants demonstrated significantly lesser learning gain compared to their middle aged and younger participants. (Table 4)

Table 3. Sex-wise distribution of average learning gain

\begin{tabular}{|c|c|c|c|c|}
\hline \multirow{2}{*}{ Average Learning gain } & \multicolumn{2}{|c|}{ Sex } & \multirow{2}{*}{ Total } & \multirow{2}{*}{$\mathbf{X}^{2}$} \\
\cline { 2 - 4 } & Female & Male & & \\
\hline$<50 \%$ & $20(21.5 \%)$ & $12(11.2 \%)$ & $32(16 \%)$ & \\
\cline { 1 - 4 } $50-75 \%$ & $18(19.35 \%)$ & $22(20.5 \%)$ & $40(20 \%)$ & \multirow{2}{*}{$\begin{array}{c}3.971 \\
\text { p- } 0.137 \mathrm{NS}\end{array}$} \\
\hline$>75 \%$ & $55(59.13 \%)$ & $73(68.22 \%)$ & $128(64 \%)$ & \\
\hline Total & $93(100 \%)$ & $107(100 \%)$ & $200(100 \%)$ & \\
\hline Average learning gain & \multicolumn{3}{|c|}{$77.98 \% \pm 23.27 \%$} \\
\hline
\end{tabular}

Table 4. Age -wise distribution of average learning gain

\begin{tabular}{|c|c|c|c|c|}
\hline \multirow{2}{*}{ Average Learning gain } & \multicolumn{2}{|c|}{ Age } & \multirow{2}{*}{ Total } & \multirow{2}{*}{$\mathrm{X}^{2}$} \\
\cline { 2 - 4 } & $<60 \mathrm{yrs}$ & $>60 \mathrm{yrs}$ & & \\
\hline$<50 \%$ & $20(14.6 \%)$ & $12(19.04 \%)$ & $32(16 \%)$ & \\
\hline $50-75 \%$ & $21(15.3 \%)$ & $19(30.15 \%)$ & $40(20 \%)$ & \multirow{2}{*}{7.786} \\
\hline$>75 \%$ & $96(70.1 \%)$ & $32(50.8 \%)$ & $128(64 \%)$ & \multirow{2}{*}{0.02} \\
\hline Total & $137(100 \%)$ & $63(100 \%)$ & $200(100 \%)$ & \\
\hline
\end{tabular}

\section{DISCUSSION}

Group education programme for diabetes was found to be effective in many studies 9-11. Also the challenges faced by diabetes patients are akin to each other. Therefore, this standardized group educational programme was planned. Keeping in mind about feasibility of patient to return back for sessions, only two sessions totalling 2-hours in duration at interval of 15 days were planned.

Studies ${ }^{9-12}$ have proven the effectiveness of patienteducation programmebyimprovement in their knowledge on the disease, glycaemic control and BMI. Changes in BMI, glycaemic control need around 6 months to exhibit, so only change in knowledge score is unveiled in this study, long term benefit study is going on. In this study we found significant improvement in knowledge score of patient after the group education sessions. Improvement in learning for all participants was outstanding.
No difference in average learning gain was found in sexes. Older Age was found to be a significant factor that affects the learning process. We therefore also invited one care giver in these sessions as support system helps in achieving better compliance and transfer of knowledge. Improvement in pre and post test score was more in those who scored less in pretest and vice versa corresponding to results of other study ${ }^{12}$. Patients felt free to ask question and express opinion regarding their sociocultural and psychological issues. Sharing each other's experiences on coping with the diabetes was appreciated by participants as it gave them a platform to discuss their psychosocial problems. Also, the programme helped them to have an open dialogue with health care providers.

With the growing burden of diabetes and out of pocket expenditure to individual, achieving the therapeutic goal and preventing the 
complications is of utmost importance. Diabetes education plays an important role in management of diabetes. This group education programme was found to be feasible, effective and acceptable to patients. This group education programme can be implemented on routine basis for all diabetic patients and one refresher session of one hour per year.

\section{CONCLUSIONS}

A dedicated group session programme implemented in an environment conducive to learning with specially designed module has a significant impact on patients' knowledge $164 \%$ participants demonstrated more than $75 \%$ learning gain) about the cause and treatment of their disease. The study can be extended to see if it impacts behaviour by tracing changes in glycaemic control.

\section{CONFLICT OF INTEREST}

There are no conflicts of interest with any of the authors

\section{REFERENCES}

1. Members [Internet]. Idf.org. 2017 [cited 22 Jun 2017]. Available from: https://www.idf.org/ournetwork/regions-members/south-east-asia/ members/94-india.html

2. Joshi SR, Das AK, Vijay VJ, Mohan V. Challenges in diabetes care in India: sheer numbers, lack of awareness and inadequate control. J Assoc Physicians India. 2008 Jun;56:443-50.

3. Ramachandran A, Snehalatha C. Current scenario of diabetes in India. J Diabetes. 2009
Mar;1 (1):18-28

4. Dorothea Orem. Nursing : Concepts of practice. 4th ed. St. Louis: Mosby-Year Book Inc.; 1991.

5. Funnell $M M$, Brown $T L$, Childs BP, Haas LB, Hosey GM, Jensen B, et al. National Standards for Diabetes Self-Management Education. Diabetes Care. 2010 Jan;33(Suppl 1):S89-96.

6. Layton S. The role of adult education in diabetes compliance [Internet]. [Athens, Georgia]: University of Georgia; 2006. Available from: https://getd.libs.uga.edu/pdfs/layton_ susan_r_200608_edd.pdf

7. Mayagah Kanj, Wayne Mitic. Promoting Health and Development: Closing the Implementation Gap. In Nairobi, Kenya,: Eastern Mediterranean Region, World Health Organization.; 2009 [cited 2017 Jun 23]. Available from: http://www.who. int/healthpromotion/conferences/7gchp/ Track1_Inner.pdf

8. Dean Schillinger, John Piette, Kevin Grumbach, Francis Wang, Clifford Wilson, Carolyn Daher, et al. Closing the loop. Am Medcial Assoc. 2003; (163):83-90.

9. Deakin T, McShane CE, Cade JE, Williams RDRR. Group based training for self-management strategies in people with type 2 diabetes mellitus. Cochrane Database Syst Rev. 2005 Apr 18;(2):CD003417.

10. Ünsal-Avdal E, Arkan B. Individual and Group Education in Diabetes and Outcomes. Aquichán. 2014 May; 14(2):138-47.

11. Lawal M, Lawal F. Individual versus group diabetes education: assessing the evidence. J Diabetes Nurs. 2016;20(7):247-250.

12. Štrajtenberger-Trbović $M$, Turk-Štrajtenberger $V$, Šekerija $M$, others. Standardized educational program in persons with type 2 diabetes on oral hypoglycemic therapy: effects on glycemic control and body mass index. Diabetol Croat. 2011;40(2):35-41. 